\title{
GEOGRAFIA DO ENSINO MÉDIO: aprendendo conceitos geográficos através da construção de maquetes
}

\section{ARTHUR BRENO STÜRMER}

arthur.sturmer@gmail.com

\section{RESUMO}

O objetivo deste trabalho é mostrar o processo de construção de maquetes para o ensino de conceitos geográficos. Baseia-se nos resultados de um projeto de ensino desenvolvido no Instituto Federal Farroupilha, com estudantes do Ensino Médio Integrado. Com metodologia assentada em oficinas pedagógicas, as orientações privilegiaram a confecção do plano tridimensional e revisão da parte conceitual básica sobre mapa, escalas, legendas e generalizações cartográficas. Houve atenção especial aos conteúdos procedimentais e atitudinais. Salienta-se como resultado o aprendizado mais consistente dos conceitos geográficos à medida que foram espacializados, tornando-se palpáveis e "próximos" dos estudantes, dando-lhes mais segurança à sua compreensão. As equipes de trabalho geraram aprendizados coletivos em uma atividade teórico-prática de contato com técnicas de representação amplamente utilizadas no meio civil e militar, com áreas do conhecimento como engenharia, arquitetura e informática. Assim, a maquete como recurso didático serviu para ensinar e aprender durante o seu processo de construção, e não apenas depois de concluída. Por possibilitar a visualização do espaço em um modelo reduzido e simplificado dos principais elementos que se quisera representar, as maquetes tornam-se um meio para organizar o conhecimento, facilitando o ensino ao docente e a aprendizagem ao estudante.

PALAVRAS-CHAVE: Aprendizagem, Cartografia, Espaço geográfico.

\section{ABSTRACT}

The aim of this paper is to show the process of building models for the teaching of geographical concepts. It is based on the results of a teaching project developed at the Farroupilha Federal Institute, with students from Integrated High School. With the methodology based on pedagogical workshops, the orientations privileged the making of the three-dimensional plan and revision of the basic conceptual part about map, scales, legends and cartographic generalizations. Special attention was given to procedural and attitudinal contents. As a result, the most consistent learning of geographical concepts is emphasized as they have been spatialized, making them palpable and "close" to students, KEYWORDS: Learning; Cartography; Geographic space. giving them more confidence in their comprehension. The work teams generated collective learning in a theoretical-practical activity of contact with representation techniques widely used in civil and military, with areas of knowledge such as engineering, architecture and informatics. Thus, the model as a didactic resource served to teach and learn during its construction process, and not only after its completion. By allowing the visualization of space in a reduced and simplified model of the main elements that it was intended to represent, the models become a means for organizing knowledge, facilitating teaching to the teacher and student learning.

\section{INTRODUÇÃO}

A maquete é um importante recurso didático, pois permite uma visão tridimensional do espaço geográfico, comumente apresentado sob a forma plana ao longo do processo de alfabetização cartográfica. Gera dificuldades para o professor 
ensinar os conceitos básicos da disciplina, como também oferece obstáculos à aprendizagem do aluno.

Construir maquetes não é um trabalho apenas do professor ou pedagogo, mas dos alunos. Aqui se entende que o conhecimento dos conceitos geográficos é construído no processo de confecção das maquetes. Não é com a maquete pronta, mas no percurso de representação das informações no plano tridimensional que as dúvidas sobre os conceitos surgem como problemas práticos para os estudantes.

Sem dúvida, a maquete permite compreender melhor os conceitos geográficos desde a alfabetização cartográfica até a discussão de problemas humanos, sociais e ambientais trazidos pelos temas que se for representar pelas maquetes.

O objetivo deste trabalho é apresentar a construção de maquetes com fins educacionais em suas diferentes etapas, abordando os conceitos básicos para o estudo, análise, compreensão e reflexão sobre o espaço. Baseia-se nos resultados de um projeto de ensino desenvolvido no Instituto Federal Farroupilha, com estudantes do Ensino Médio Integrado, Curso Técnico em Informática Integrado, do Instituto Federal Farroupilha - IFFar, campus Frederico Westphalen-RS.

Selecionou-se uma turma do Técnico em Informática, para que, conhecendo um pouco de aplicativos de animação 3D, se fizesse uma "ponte" para o aprendizado das curvas de nível ou linhas hipsométricas de representação do relevo bem como compreendessem a elaboração de um modelo básico de maquete em realidade aumentada, conforme apresenta Sunaga (2019).

A turma que veio a participar do projeto de ensino foi o primeiro ano do Técnico em Informática, para o qual está previsto como conteúdo programático os conceitos de espaço geográfico, região, paisagem, território, lugar, rede, arranjo espacial e outros considerados fundamentais para o aprendizado dos conteúdos dos anos seguintes, como escala cartográfica (gráfica, numérica), escala vertical, escala horizontal e perfil geomorfológico.

\section{PERCURSO METODOLÓGICO}

Por se tratar de um projeto de ensino, a metodologia de partida não deveria lembrar as atividades de sala de aula. O próprio ambiente poderia ser outro, no entanto, o espaço ganhou nova função com as atividades no formato de oficinas pedagógicas, que foram bem acolhidas desde o início. Havia a preocupação em se oferecer uma atividade instigante para os alunos e que eles se sentissem estimulados para fazer as maquetes.

Ao invés de usar da exposição oral tradicional sobre como proceder tecnicamente com os materiais, entendeu-se trabalhar com pequenos grupos, cada qual responsável por uma maquete de tema específico. 0 método de orientação, no caso, foi adotado como substituto à aula expositiva.

Foram nove maquetes confeccionadas por equipes de trabalho compostas de, no máximo, quatro alunos. Previu-se o tempo correspondente a uma aula no horário normal (turno matutino) e duas tardes no contraturno (turno vespertino), totalizando aproximadamente doze horas.

Os principais materiais foram requisitados aos alunos, seja para conseguirem emprestados, seja para adquirirem. Consistiram de: a) materiais de escola: mapas temáticos, retroprojetor, lâmina para impressão, caneta esferográfica, lápis, papel 
pardo papel carbono, tesoura, estilete, alfinete; b) materiais de livraria e construção: placas de Eucatex, folhas de isopor, massa corrida, cola de isopor, espátula pequena, pincéis, tintas de várias cores, lixas; c) materiais diversos: tubos de caneta, agulhas grandes, vela, fósforo. Aqueles que tiveram custo mais alto, os professores contribuíram, uma vez que serviria para uso dos demais colegas e ao ensino e aprendizagem de estudantes de outras turmas, cursos e escolas.

As atividades foram finalizadas no mês de agosto de 2018, sendo alvo de avaliação da disciplina de Geografia do Ensino Médio Integrado a participação em todas as etapas de construção das maquetes e a apresentação dos resultados na VII Mostra Regional de Ciências do campus Frederico Westphalen. Esta acontece em parceria com a 20a Coordenadoria de Educação do estado do Rio Grande do Sul (CRE), envolve também as redes municipais e particulares de ensino, logo contempla o Ensino Fundamental, Ensino Médio, incluído o a Educação Profissional Técnica de Nível Médio (IFFAR, 2018).

\section{PRINCIPAIS RESULTADOS}

$\mathrm{Na}$ interação dos estudantes com seu objeto de estudo em construção - as maquetes -, desenvolveram habilidades cognitivas, motoras e artísticas, dentre o domínio visual do espaço.

Almeida (2003, p. 77) aponta que: "O uso de maquetes favorece a passagem da representação tridimensional para a bidimensional, por possibilitar o domínio visual do espaço, a partir de um modelo reduzido." Assim, a maquete, por ser algo mais "concreto" para o estudante, facilita a aprendizagem (e o ensino) de conceitos geográficos num movimento progressiva de abstração até chegar a compreender os mapas.

Não é por estar no Ensino Médio que se dá para supor que todos os estudantes dominem a leitura de mapas. Então a maquete cumpre a função de ser suporte à aprendizagem de conceitos e aperfeiçoamento da habilidade de leitura do espaço do concreto para o abstrato.

No trabalho de construção de maquetes, merecem destaque as seguintes resultados, em termos de aprendizagem, para os estudantes:

1. Aprendizado mais consistente sobre os conceitos geográficos, então espacializados, palpáveis e "próximos", dando mais segurança à sua compreensão;

2. Motivação para o trabalho em equipe e aprendizado coletivo em uma atividade teórico-prática considerada "diferente" do comum e agradável;

3. Contato com técnicas de representação reais, amplamente utilizadas no meio civil e militar, atingindo áreas do conhecimento que vão da cartografia, engenharia e arquitetura ao design e animação 3D.

Houve dificuldades iniciais, mas superadas, em relação ao recorte das curvas de nível nas placas de isopor e à coordenação interna dos grupos. Essas dificuldades podem ser lidas como desafios para cada um dos membros da equipe.

Cavalcanti (2012) consideraria esse um desafio para os professores, pois thes exige pensar o ensino e a medição pedagógica que contemple a diversidade de cultura dos alunos e de cada aluno: 
Pode-se entender que essa diversidade vai além do conjunto de conhecimentos, valores, significados que os alunos carregam consigo, pois diz respeito também à diferença de estilos, ritmos e capacidades individuais internas de aprendizagem. (...) Nesse sentido, é relevante, ainda que não suficiente, para os professores de Geografia enfrentar o desafio de se considerar, entre outras, a "cultura geográfica" dos alunos. (CAVALCANTI, 2012, p. 68).

Nas oficinas, era perceptível o "confronto" entre o que os estudantes já sabiam e o saber geográfico sistematizado próprio da cultura escolar. E ele se produziu justamente ao aprender a utilizar a nomenclatura especializada na cartografia e no ponto alto projeto, a saber, a definição de temas para o que vinham construindo. A solução neste momento foi empreender um esforço de pesquisa.

Para Barberà et al (2004), há certa estabilidade nos conceitos prévios, o que torna as novas aprendizagens facilmente esquecíveis. Para se contornar tal dificuldade, sugere que a pesquisa dirigida planejada para orientar a construção de conhecimentos tenha caráter cíclico (repetitivo, insistente), com crescente generalização, abstração e conceitualização. A repetição e insistência, segundo o autor, são sobre os "conhecimentos científicos considerados básicos e fundamentais" (Ibid., p. 107).

Aqui se entende que os conceitos geográficos são básicos e fundamentais ao ponto de justificar novas estratégias de ensino, como a construção de maquetes, mesmo que os estudantes e professores precisem se dedicar mais que em outras atividades. Por exemplo, a fase ou etapa que se mostrou mais estimulante, embora tensa para os estudantes, foi a representação dos temas por eles escolhidos para as maquetes.

São eles, selecionados livremente pelos estudantes, em uma lista apresentada pelos professores:

Lista de temas para maquetes:

1 - Mapa dos complexos regionais

2 - Estrutura geológica do Brasil

3 - Recursos minerais do Brasil

4 - Bacias hidrográficas do Brasil

5 - Vegetação original do Brasil

6 - Climas do Brasil

7 - Brasil PIB regional

8 - Brasil IDH regional

9 - Mapa da violência Brasil

Cada tema ficou a cargo de três a quatro estudantes, que, após a 5 a fase de construção da maquete, fariam fixariam o tema na 6a fase, quando então a coloririam de acordo com a pesquisa sobre dados variados, de caráter físico, humano, social, econômico, ambiental, produtivo, etc.

\section{A CONSTRUÇÃO DAS MAQUETES}


A construção das maquetes pode ser ilustrada suscintamente em etapas que variam conforme o grau de detalhamento e objetivos a que se propõe. Abaixo serão apresentadas seis fases principais que são utilizadas na confecção das maquetes, acompanhadas das respectivas da respectiva ilustração a partir de imagens coletadas durante o desenvolvimento das atividades do projeto de ensino.

- 1a fase: cópia de dados altimétricos, utilizando lâmina com o mapa do Brasil e papel vegetal, em que os estudantes precisaram de habilidade manual e precisão ao retirar os dados para compor o mapa base (Figura 1).

Figura 1 - Dados altimétricos

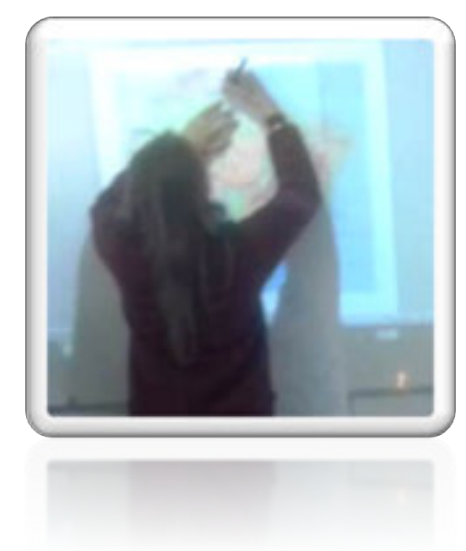

Fonte: Pesquisa de campo, 2018.

- 2a fase: utilização do mapa base com a escala já calculada, para transferir dados altimétricos às placas de isopor marcando-as com furos feitos com agulha e papel carbono (Figura 2).

Figura 2 - Transferência de dados

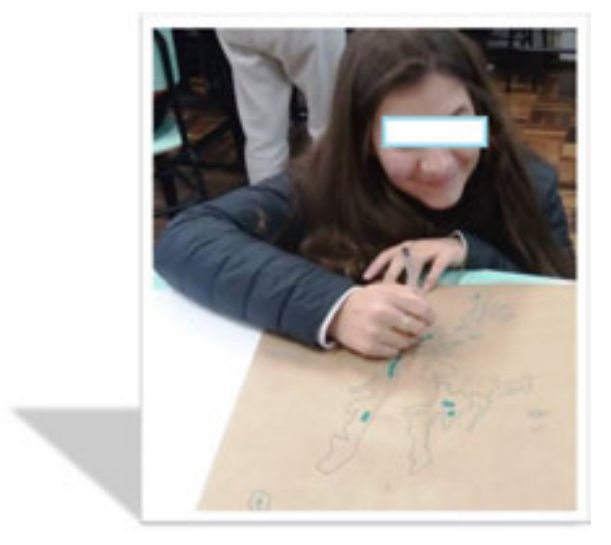

Fonte: Pesquisa de campo, 2018.

- 3a fase: recorte das placas de isopor com estilete, contornando as curvas hipsométricas em detalhes (Figura 3). 
Figura 3 - Recorte das placas de isopor

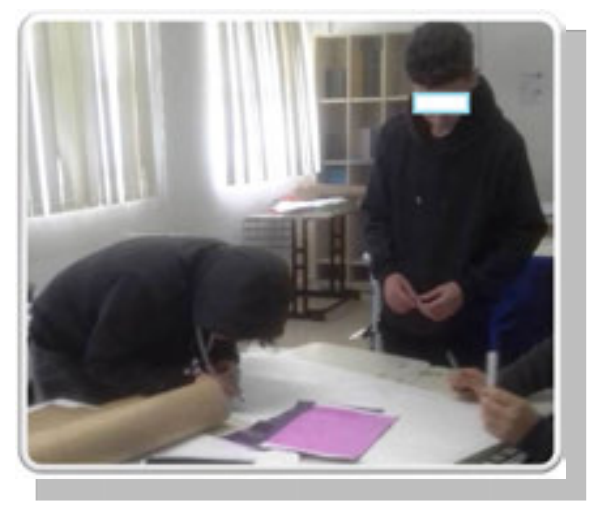

Fonte: Pesquisa de campo, 2018.

- 4a fase: sobreposição das placas de isopor, conforme hipsometria - a fase mais de maior complexidade, em função da orientação (N-S; L-O) e posicionamento correto das partes pequenas. Os estudantes puseram à prova seus conhecimentos de geomorfologia e compartimentos do relevo brasileiro (Figura 4).

Figura 4-Hipsometria

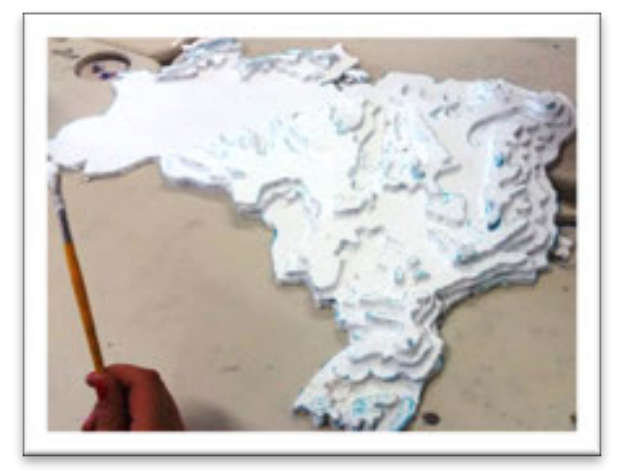

Fonte: Pesquisa de campo, 2018.

- 5a fase: modelagem do relevo com massa corrida, preenchendo os espaços entre as placas de isopor. No trabalho minucioso foram testadas as habilidades de representar com fidelidade os detalhes resultantes dos processos naturais (Figura 5).

Figura 5 - Modelagem

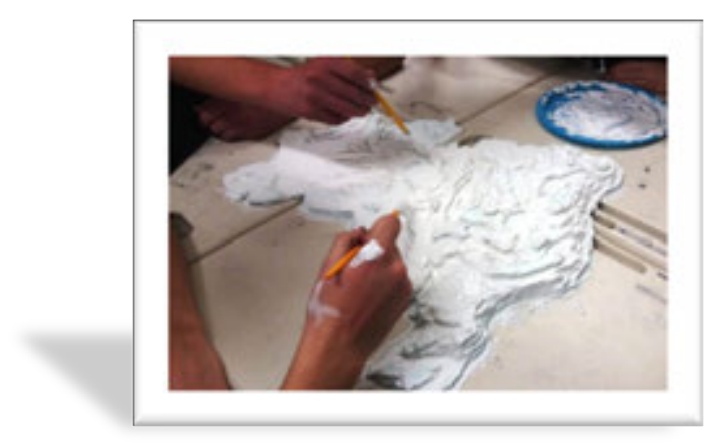


Fonte: Pesquisa de campo, 2018.

- 6a fase: ao final da quinta fase de construção das maquetes teve-se a certeza de que se havia ensinado e aprendido conceitos geográficos importantes. A última fase, com a tematização de cada maquete (Figura 6).

Figura 6 - Inserção dos temas às maquetes

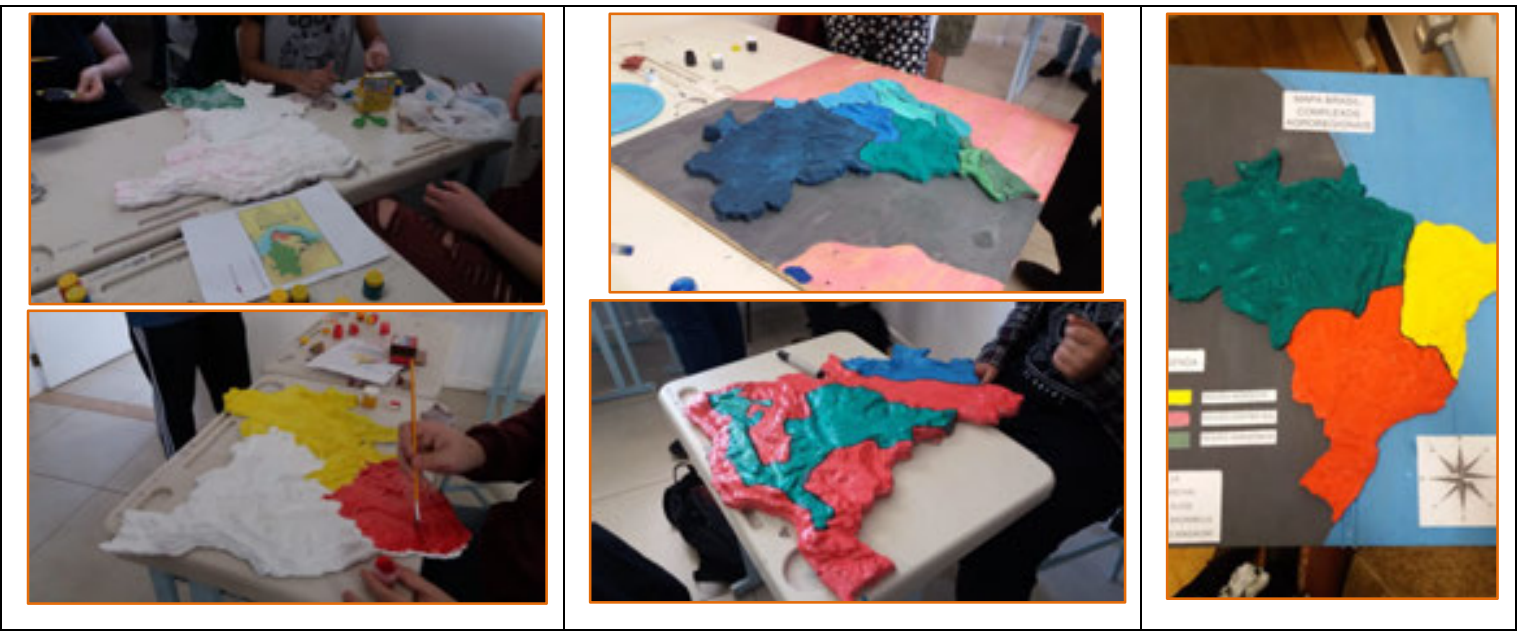

Fonte: Pesquisa de campo, 2018.

A essa altura do desenvolvimento do projeto esteve claro que a última fase viria naturalmente a agregar assuntos ou temas que auxiliariam a recompor aspectos de uma totalidade, cuja aproximação vinha sendo feita nas fases anteriores e tendo como base seus conhecimentos e conceitos prévios.

Assinala-se que o produto final nem de longe fora imaginado como possível aos estudantes até que acontecesse. A orientação dos professores, o trabalho em equipe $\mathrm{e}$ os materiais disponíveis foram três fatores indispensáveis para o sucesso das atividades.

\section{CONSIDERAÇÕES FINAIS}

Assim, a maquete como recurso didático serviu para ensinar e aprender durante o seu processo de construção, e não apenas depois de concluída. Maquetes prontas são encontradas em livrarias e lojas especializadas, mas não serviriam à proposta do projeto de ensino.

O que se pretendia era ensinar conceitos geográficos ao longo da construção das maquetes, à semelhança de um desafio ou problema colocado aos estudantes, ao invés de simplesmente apresentar modelos prontos para visualizar o espaço geográfico e discutir temas variados.

Pôde-se confirmar o aprendizado de diversos tipos de conteúdos, além dos conceitos geográficos. Isso porque nas diferentes fases de construção das maquetes foi preciso mobilizar os conceitos de espaço geográfico, região, paisagem, território, lugar, rede, arranjo espacial, bem como habilidades e competências ligadas ao trabalho sequencial, minucioso e em equipe requerendo coordenação e divisão das tarefas de pesquisa, construção, desenho, colagem, pintura e outros. 
Alguns conteúdos previstos para serem abordados através do projeto foram trabalhados de maneira não formal e prática, especialmente aqueles mais difíceis aos estudantes: escala cartográfica (gráfica, numérica), escalas vertical e horizontal, além do perfil geomorfológico.

Acredita-se que a utilização de uma estratégia didática como a construção de maquetes tenha contribuído para que, como dizem Nogueira e Carneiro (2013, p. 132), "os sujeitos-alunos possam compreender como funcionam as relações estruturais da sociedade" exercitando a "capacidade de composição da totalidade (natural, social, política, econômica, histórica, cultural etc.)" que vez ou outra apareceram nas nove maquetes temáticas propostas.

A dúvida que ronda muitos professores de Geografia do Ensino Médio é quanto à utilidade de uma metodologia que se usa no Ensino Fundamental, com crianças. Os resultados obtidos aqui por meio de projeto mostraram a eficiência da construção de maquetes para aprender os conceitos geográficos.

A despeito de não ser uma atividade tão comum no Ensino Médio quanto ela poderia ser, viu-se que trouxe resultados importantes para quem cursa o Ensino Médio Integrado, pois oportuniza a combinação de teoria e prática, de um lado, e a integração de conhecimento geral e conhecimento técnico, de outro.

É possível que atividades que desorganizem as salas de aula, gerem barulho e despendam recursos sejam vistas com maus olhos pelos colegas de trabalho. Também é provável que nem todas as maquetes sejam apresentadas ao público ou que, mostradas em um evento, depois não encontrem lugar para ficar e permaneçam guardadas num canto da instituição ou, geralmente, na biblioteca da escola antes de ter destino ignorado.

O fato é que seu valor está no que proporcionou de aprendizado em Geografia, Biologia, Cartografia, cálculos matemáticos, artes plásticas e outras áreas do saber; a visão integrada dos fenômenos, sua correspondente expressão espacial, complexa, materializada na maquete.

Ao professor, o valor primeiro reside na capacidade que desenvolve em fazer a mediação pedagógica com o material adequado à inter-relação entre os saberes, com vistas à aproximação da teoria com a prática e a transformação do aluno passivo em "sujeito-aluno".

\section{REFERÊNCIAS}

1. ALMEIDA, R. D. de. Do desenho ao mapa: iniciação cartográfica na escola. 2. ed. São Paulo: Contexto, 2003. (Caminhos da Geografia)

2. CAVALCANTI, L. de S. Ensino de geografia e diversidade: construção de conhecimentos geográficos escolares e atribuição de significados pelos diversos sujeitos do processo de ensino. In: CASTELLLAR, S. (Org.). Educação geográfica: teorias e práticas docentes. 3. ed. São Paulo: Contexto, 2012. p. 66-78. (Novas abordagens. GEOUSP; v. 5)

3. IFFAR. Mostra Regional de Ciências: Apresentação da Mostra de Ciências. Disponível em: <http://mostra.fw.iffarroupilha.edu.br/2018/sobre>. Acesso em: 27 ago. 2019.

4. LESTEGÁS, F. R. Propostas para uma didática do espaço urbano: um enfoque crítico e construtivista. In: BARBERÀ, E. et al. 0 construtivismo na prática. Trad. Magda S. Chaves. Porto Alegre: Artmed, 2004. p. 103-115. (Col. Inovação pedagógica; v. 9) 
5. NOGUEIRA, V.; CARNEIRO, S. M. M. Educação geográfica e formação da consciência espacial-cidadã. Curitiba: Ed. UFPR.

6. SUNAGA, A. Crie mapas 3D em realidade aumentada. Publicado em 17 de agosto de 2019. Vídeo-aula, 2'18". Disponível em: <https://www.youtube.com/watch?v=575PCeigf2I\&feature=youtu.be>. Acesso em: 27 ago. 2019. 